\title{
All terrain vehicle ownership, use, and self reported safety behaviours in rural children
}

\author{
Lynne Warda, Terry P Klassen, Norma Buchan, Amy Zierler
}

\begin{abstract}
Objectives-To describe all terrain vehicle (ATV) ownership, access, use, and safety behaviours in rural Manitoba children. Methods-Questionnaire administered to a convenience sample of grade 6 students attending an agricultural fair.

Results-162 grade 6 children participated. The mean age was 11.4 years, and $46 \%$ were male. 125 students $(77 \%)$ reported having access to ATVs, including 69 four wheeled, 24 three wheeled, and four both three and four wheeled ATVs. ATV experience was reported in 95 students, significantly more often in males and among those with a family owned ATV, with no difference between children living on a farm and in a town. Use of helmets and protective clothing was inadequate (10-40\%), and dangerous riding habits common, with males and children living on a farm reporting significantly fewer desirable behaviours.

Conclusions-ATVs are commonly used by children in rural Manitoba, with inadequate protective gear and dangerous riding habits. Mandatory rider training, consumer and dealer education, and legislation enforcement could improve ATV safety in this population.

(Injury Prevention 1998;4:44-49)
\end{abstract}

Keywords: all terrain vehicles; helmet use; adolescents; rural safety

All terrain vehicles (ATVs) are motorized three or four wheeled cycles with large, low pressure tires, designed for a single operator riding in off-road areas (see fig 1). These vehicles, similar in size to motorcycles, were designed and marketed in the late 1960s and early 1970s for occupational use on farms and other off-road areas, as smaller, more mobile and more economical alternatives to the tractor and truck. ${ }^{12}$

Sales rapidly increased in the early 1980s, when recreational use of ATVs became popular. ${ }^{2-4} \mathrm{~A}$ dramatic rise in ATV injuries and deaths was soon documented, out of proportion to the number of vehicles sold. The most concerning rise occurred in the pediatric population, with many children and youth requiring hospitalization for serious injuries. ${ }^{45}$ In 1986, at the peak of the epidemic, there were over 300 deaths and 108000 injuries related to ATVs in the US. ${ }^{6}$ These alarming injury trends prompted a ban on the sale of three wheeled vehicles and increased professional and public awareness of the dangers of ATV riding among children. ${ }^{4578}$

Injuries and deaths then steadily declined, as documented by annual US Consumer Product Safety Commission (CPSC) data. In 1994 there were 173 deaths reported and an estimated 59200 injuries in the US. However, the CPSC reported in 1995 that children under the age of 16 still accounted for $40 \%$ of deaths and injuries. ${ }^{6}$ ATV injuries and deaths remain a significant health problem for children and youth in Canada. The Canadian Hospitals Injury Reporting and Prevention Program, which prospectively collects injury data from 15 Canadian hospitals (10 pediatric and five general), documented 831 ATV injuries between 1991 and 1996 (table 1). Almost one third of those injured required admission to hospital. ${ }^{9}$ Every year there are over 30 hospital admissions for ATV injuries in Manitoba, and one or two deaths occur every year (Manitoba Health Services Commission, unpublished data).

ATV sales are steadily climbing worldwide, having temporarily suffered as a result of negative publicity. In the US an estimated 2.5 million ATVs were in use in 1993, and in 1996 over 300000 new ATVs were sold. ATVs are popular recreational vehicles for the residents of rural and northern areas, and are also commonly used for local transportation, farming and other rural occupations. On 3 January 1997, 2595 vehicles were registered in Manitoba (total population 1.1 million); however the actual number of ATVs in the province is unknown, due to poor compliance with, and enforcement of, mandatory vehicle registration (Manitoba Public Insurance Vehicle Registration Statistics, unpublished data). International ATV enthusiasm is evidenced by increasing activity on the world wide web. There are several comprehensive user web sites, most notably www.atving.com, based in North America, with links to Australia, New Zealand, continental Europe, and Japan. Numerous sport and racing ATVs are aggressively marketed on the websites of the six major manufacturers, along with snowmobiles and jet skis. Available models vary considerably in size and power, with engine displacements ranging from $60 \mathrm{cc}$ to $400 \mathrm{cc}$, some capable of achieving speeds up to $70 \mathrm{mph}$.

Patterns of ATV ownership, access, and use have not been reported in the literature. Published data describing ATV safety behaviours, such as wearing a helmet and other protective clothing, carrying passengers, or riding on public roads have been obtained only from studying injured riders. Baseline prevalence of 


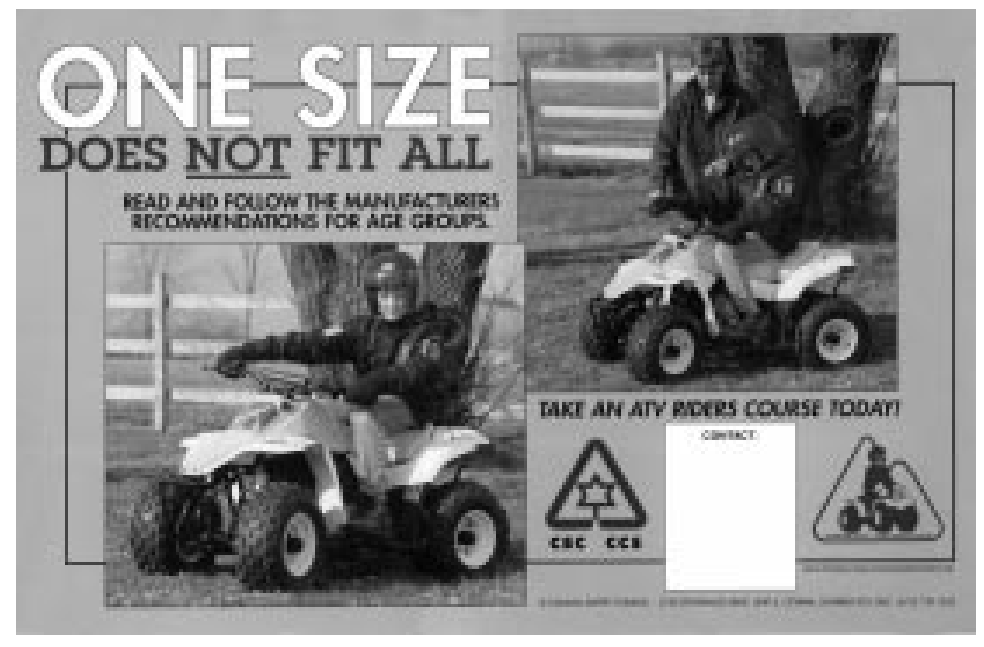

Figure 1 Safety poster showing ATVs (picture courtesy of the Canada Safety Council).

these safety behaviours is unknown. Therefore, this survey was conducted to characterize ATV ownership, access and use, and self reported safety behaviours in a rural population of children and adolescents to help focus future preventive interventions.

Grade $\_$School $\_$Town
Age $\_$Sex $\_$Height $\_$Weight $\_$

- Do you live on a farm? $\square$ or in a town? $\square$

- Have you ever operated an ATV? Yes $\square \quad$ No $\square$

- Does your family own an ATV? Yes $\square \quad$ No $\square$

If not, whose do you use? $\quad$ Friends $\square \quad$ Neighbours $\square \quad$ Relatives $\square$

- Do you give rides on your ATV? Yes $\square \quad$ No $\square$

- Do you know what size of machine you drive? Yes $\square \quad$ No $\square$ Smaller than 90 cc $\square \quad$ Larger than 90 cc $\square \quad$ If larger

- Is your machine a three wheeler $\square$ ? $\quad$ Four wheeler $\square$ ?

- Do you wear a helmet? $\quad$ Always $\square \quad$ Sometimes $\square \quad$ Never $\square$

- Do you wear protective clothing?

$\begin{array}{llll}\text { Eye protection } & \text { Always } \square & \text { Sometimes } \square & \text { Never } \square \\ \text { Boots (with heel) } & \text { Always } \square & \text { Sometimes } \square & \text { Never } \square \\ \text { Gloves (leather) } & \text { Always } \square & \text { Sometimes } \square & \text { Never } \square \\ \text { Long sleeves } & \text { Always } \square & \text { Sometimes } \square & \text { Never } \square \\ \text { Long pants } & \text { Always } \square & \text { Sometimes } \square & \text { Never } \square\end{array}$

- Do you ride on public roads?

Always $\square \quad$ Sometimes $\square \quad$ Never $\square$

Figure 2 Questionnaire given to children attending IM-PACT exhibit.

\section{Methods}

An annual farm exhibition is organized by the Manitoba Association of Agricultural Societies. In the spring of 1996 letters of invitation were sent to 55 grade 6 classes (average age 11-12 years) from a rural school division to attend the fair on a school field trip in June. Injuries Manitoba-Prevention of Adolescent and Childhood Trauma (IM-PACT) was invited to hold an exhibit on ATV safety. Eleven schools attended the fair. Each class attended the exhibits in the Farm Safety Trail in sequence, as a group. Children attending the IM-PACT exhibit were invited to complete a short questionnaire about ATV access and use and safety behaviours (fig 2). Only grade 6 respondents were included in the survey sample; all other grades were excluded. Relative risk (RR) with 95\% confidence intervals (CI) were calculated for each proportion using Confidence Interval Analysis Version 1.1, to examine sex and residence (farm or town) differences in ATV ownership, use and safety behaviours. Bonferroni correction for multiple comparisons was not performed because these data were considered hypothesis generating rather than hypothesis testing.

\section{Results}

Of the 191 students completing the survey, 162 were in grade 6 . Although the response rate is not known, exhibit staff estimate that fewer than $10 \%$ of children attending the exhibit did not complete the survey. The mean age for the grade 6 students was 11.6 years (SD 0.67, range 10-14 years, two unknown). Forty six per cent were male and $54 \%$ were female (four unknown); $46 \%$ reported living on a farm and $54 \%$ in a town (three unknown). A summary of significant risk factors for ATV ownership, use and safety behaviours is presented in table 2 .

ATV OWNERSHIP AND USE

Altogether $77 \%$ of students reported having access to an ATV, either a family ATV or one belonging to a friend, neighbour, or relative. Forty eight students $(30 \%)$ reported having a family ATV. Students living on a farm were significantly more likely to have a family owned ATV than students living in a town, $41 v 21 \%$ respectively (RR $1.96,95 \%$ CI 1.20 to 3.22 ). This difference was significant for females (RR $2.80,95 \%$ CI 1.26 to 6.21 ), but not for males. Many students reported using ATVs belonging to friends (48), neighbours (11), or relatives (49). Of the 65 students knowing the size of the engine, 30 were smaller than $90 \mathrm{cc}$ and 35 were larger than $90 \mathrm{cc}$. Sixty nine students reported using four wheeled vehicles and 24 reported using three wheeled vehicles. Four students reported using both three and four wheeled models.

ATV EXPERIENCE

Ninety five students (59\%) reported having "ever operated" an ATV. Significantly more males $(77 \%)$ than females $(41 \%)$ had ATV experience (RR $1.86,95 \%$ CI 1.40 to 2.47 ). This difference was significant both for town 
Table 1 Canadian Hospitals Injury Reporting and Prevention Program ATV injury surveillance (1991-95): nature of injury and body part injured

\begin{tabular}{|c|c|c|c|}
\hline Nature of injury & No & & $\%$ of injuries \\
\hline $\begin{array}{l}\text { Abrasion, bruising, or } \\
\text { inflammation }\end{array}$ & 396 & & 34.2 \\
\hline Trunk & & 88 & \\
\hline Lower leg/knee & & 70 & \\
\hline Head & & 70 & \\
\hline Ankle/foot & & 50 & \\
\hline Upper leg/hip & & 30 & \\
\hline Forearm/elbow & & 27 & \\
\hline Wrist/hand & & 23 & \\
\hline Shoulder/upper arm & & 22 & \\
\hline Internal organ & & 9 & \\
\hline Lung/larynx & & 7 & \\
\hline Fracture & 381 & & 32.9 \\
\hline Forearm/elbow & & 99 & \\
\hline Lower leg/knee & & 51 & \\
\hline Head/neck & & 48 & \\
\hline Shoulder/upper arm & & 46 & \\
\hline Ankle/foot & & 41 & \\
\hline Trunk & & 31 & \\
\hline Wrist/hand & & 30 & \\
\hline Upper leg/hip & & 26 & \\
\hline Spine & & 9 & \\
\hline Cut or laceration & 139 & & 12.0 \\
\hline Head/face/neck & & 72 & \\
\hline $\mathrm{Hip} / \mathrm{leg} /$ foot & & 38 & \\
\hline Shoulder/arm/hand & & 18 & \\
\hline Trunk & & 7 & \\
\hline Internal organ & & 4 & \\
\hline Sprain or strain & 85 & & 7.3 \\
\hline Concussion & 45 & & 3.9 \\
\hline Minor head injury & 20 & & 1.7 \\
\hline Multiple system trauma & 19 & & 1.6 \\
\hline Burn & 19 & & 1.6 \\
\hline Dislocation or subluxation & 15 & & 1.3 \\
\hline Crush & 10 & & 0.9 \\
\hline Hemorrhage & 10 & & 0.9 \\
\hline Brain & & 4 & \\
\hline Eye & & 2 & \\
\hline Lung & & 2 & \\
\hline Skull & & 2 & \\
\hline Dental & 7 & & 0.6 \\
\hline Amputation/near amputation & 5 & & 0.4 \\
\hline Other & 7 & & 0.6 \\
\hline Total & & 1158 & 100.0 \\
\hline
\end{tabular}

Note: up to three injuries may be specified for each record; 234 patients $(28.1 \%)$ sustained more than one injury.

and farm residence. Students with a family owned ATV were significantly more likely to be experienced riders (94\%) than those with no family ATV (56\%) (RR 1.70, 95\% CI 1.40 to 2.00). There was no difference in ATV experience between students living on a farm

Table 2 Significant risk factors for ATV ownership, experience, and safety behaviours among young rural adolescent ATV riders (referent group noted in parentheses)

\begin{tabular}{ll}
\hline & $R R(95 \%$ CI) \\
\hline ATV ownership & $1.96(1.20$ to 3.22$)$ \\
$\quad$ Students living on a farm (town) & $2.80(1.26$ to 6.21$)$ \\
$\quad$ Females living on a farm (females, town) & $1.86(1.40$ to 2.47$)$ \\
ATV experience & $1.89(1.21$ to 2.95$)$ \\
$\quad$ Male gender (female) & $1.92(1.34$ to 2.75$)$ \\
$\quad$ Males living on a farm (female, farm) & $1.70(1.40$ to 2.00$)$ \\
$\quad$ Males living in a town (female, town) & \\
Family owned ATV (no family owned ATV) & \\
Safety behaviours & $1.80(1.03$ to 3.12$)$ \\
$\quad$ Always wearing a helmet & $2.01(1.07$ to 3.81$)$ \\
$\quad$ Students living in a town (farm) & \\
$\quad$ Males living in a town (males, farm) & $1.74(1.05$ to 2.87$)$ \\
Always or sometimes wearing eye protection & $1.88(1.04$ to 3.40$)$ \\
$\quad$ Students living in a town (farm) & \\
$\quad$ Males living in a town (males, farm) & $4.55(1.42$ to 14.5$)$ \\
Always wearing gloves & $2.66(1.02$ to 6.94$)$ \\
$\quad$ Male gender (female) & \\
$\quad$ Males living on a farm (females, farm) & $1.93(1.12$ to 3.32$)$ \\
$\quad$ Always or sometimes riding on public roads & $2.20(1.06$ to 4.60$)$ \\
$\quad$ Male gender (female) & \\
$\quad$ Males living on a farm (females, farm) & \\
\hline
\end{tabular}

$(59 \%)$ and in a town $(60 \%)$. Forty six per cent of students reported giving rides on their ATVs.

\section{SAFETY BEHAVIOURS}

Self reported ATV safety behaviours are seen in table 3. There were no gender differences for use of a helmet, long sleeves or pants, boots, or protective eyewear. Males were more likely to always wear gloves (29\%) than females (6\%) (RR 4.55, 95\% CI 1.42 to 14.50 ), even among students living on a farm (RR 2.66, 95\% CI 1.02 to 6.94$)$. Males were more likely to always or sometimes ride on public roads $(53 \%)$ than females $(27 \%)$ (RR 1.93, 95\% CI 1.12 to 3.32), even among students living on a farm (RR 2.20, 95\% CI 1.06 to 4.60 ).

Students living in a town were more likely to always or sometimes wear eye protection $(49 \%)$ than students living on a farm $(28 \%)$ (RR 1.74, 95\% CI 1.05 to 2.87). This difference persisted for males (RR 1.8, 95\% CI 1.04 to 3.40 ). Students living in a town were also more likely to always wear a helmet (44\%) than students living on a farm (25\%) (RR 1.80, $95 \%$ CI 1.03 to 3.12). Helmet use was more common among males living in a town $(57 \%)$ than males living on a farm (28\%) (RR 2.01, $95 \%$ CI 1.07 to 3.81 ). The majority of students living in a town would "never" ride on public roads $(78 \%)$, as compared with $51 \%$ of those living on a farm (RR $1.52,95 \%$ CI 1.11 to 2.09).

\section{Discussion}

Although the risks of ATV riding in children have been well documented, patterns of ATV ownership and use among children and their use of protective equipment have not been previously described. Therefore our study documents a number of new findings. Contrary to national and international guidelines published by safety organizations, governments and industry, these rural children are riding ATVs at a very young age, they are riding three wheeled vehicles (now banned in the US), most are not wearing helmets or other protective clothing, and many admit to dangerous riding habits, including riding double and riding on public roads.

The primary limitations of this survey are its small size and its non-random convenience sampling frame. The school division sampled is located in a rural region of Manitoba known to have a significant ATV riding population, similar to other rural areas within the province. We do not know if classes or schools not attending the fair differed from the attending classes or schools, although systematic bias resulting from this would be unlikely. Females were over-represented (52\%), particularly those living in a town (59\%), as compared with corresponding population data $(48 \%) .{ }^{10}$ This gender bias may have influenced analyses of residence differences, so subgroup analyses were performed. Volunteer respondents may have been more likely to ride ATVs, hence overestimating ATV access and use. The self report data obtained in the questionnaire is 
Table 3 Self reported protective equipment use among young adolescent ATV riders (10-14 years of age); results are number (\%)

\begin{tabular}{|c|c|c|c|c|c|c|c|c|c|c|c|c|}
\hline & \multicolumn{3}{|l|}{ Always } & \multicolumn{3}{|l|}{ Sometimes } & \multicolumn{3}{|l|}{ Never } & \multicolumn{3}{|c|}{ No of respondents } \\
\hline & Male & Female & Total & Male & Female & Total & Male & Female & Total & Male & Female & Total \\
\hline Helmet & $26(41.3)$ & $12(26.1)$ & $38(34.9)$ & $21(33.3)$ & $21(45.7)$ & $42(38.5)$ & $16(25.4)$ & $13(28.3)$ & $29(26.6)$ & 63 & 46 & 109 \\
\hline Eye protection & $7(11.7)$ & $3(6.4)$ & $10(9.3)$ & $21(35.0)$ & $12(25.5)$ & $33(30.8)$ & $32(53.3)$ & $32(68.1)$ & $64(59.8)$ & 60 & 47 & 107 \\
\hline Boots & $12(19.7)$ & $9(18.4)$ & $21(19.1)$ & $26(42.6)$ & $14(28.6)$ & $40(36.4)$ & $23(37.7)$ & $26(53.1)$ & 49 (44.5) & 61 & 49 & 110 \\
\hline Gloves & $18(29.0)$ & $3(6.4)$ & $21(19.3)$ & $18(29.0)$ & $11(23.4)$ & $29(26.6)$ & $26(41.9)$ & $33(70.2)$ & $59(54.1)$ & 62 & 47 & 109 \\
\hline Long sleeves & $20(32.3)$ & $16(32.0)$ & $36(32.1)$ & $27(43.5)$ & $24(48.0)$ & $51(45.5)$ & $15(24.2)$ & $10(20.0)$ & $25(22.3)$ & 62 & 50 & 112 \\
\hline Long pants & $24(38.1)$ & $21(42.0)$ & $45(39.8)$ & $28(44.4)$ & $20(40.0)$ & $48(42.5)$ & $11(17.5)$ & $9(18.0)$ & $20(17.7)$ & 63 & 50 & 113 \\
\hline $\begin{array}{l}\text { Rides on public } \\
\text { roads }\end{array}$ & $4(7.0)$ & $0(0)$ & $4(4.0)$ & $26(45.6)$ & $12(27.3)$ & $38(37.6)$ & $27(47.4)$ & $32(72.7)$ & $59(58.4)$ & 57 & 44 & 101 \\
\hline
\end{tabular}

limited by potential recall bias and possible under-reporting of undesirable risky behaviours. Despite its limitations, this survey provides the first reported data on ATV access, use, and baseline safety behaviours in a population of rural children.

ATV access and use was remarkably common. Over $75 \%$ of children surveyed had access to an ATV, one third of families owned an ATV, and almost two thirds of children reported ATV experience. Manitoba law requires that off-road vehicle riders under the age of 14 be "supervised, accompanied by and, at all times, within clear view of a parent or person who is at least 18 years old and authorized by the parent". ${ }^{11}$ All but three of the children in our sample were less than 14 years of age and we suspect that few were supervised in this manner.

Given current age recommendations, our respondents were surprisingly experienced. The Canadian Pediatric Society's Injury Prevention Committee and the American Academy of Pediatrics Committee on Injury and Poison Prevention published statements in 1987 recommending a ban on ATV use by children less than 14 years of age. ${ }^{4}$ ATVs are powerful, heavy machines, often outweighing a child by more than five times, and they are inherently unstable due to their high center of gravity. Adequate physical size and strength as well as mature motor and cognitive skills are required for safe driving. ${ }^{12}$

In our sample of experienced young riders, over half of the ATVs for which size was known were adult size (over $90 \mathrm{cc}$ ). The US CPSC has issued a warning that "young people under the age of 16 should never operate an adult size ATV (over $90 \mathrm{cc}$ engine size)". ${ }^{12}$

The number of three wheeled vehicles reported in this small sample is also of concern, given the much greater hazards of such vehicles, especially when operated by children. Although the first marketed ATVs were three wheeled, a four wheeled design was soon introduced due to significant instability of its three wheeled predecessor. ${ }^{213-15}$ The sale of three wheeled vehicles has been banned in the US since the 1988 consent decree between CPSC and ATV distributors. ${ }^{16}$ In Canada, new three wheeled vehicles are no longer sold; however it remains legal to sell, trade, register, and insure three wheeled vehicles. In 1995 in Manitoba 746 of the 2711 ATVs registered were three wheeled (Manitoba Public Insurance Registration Statistics, 1991-95, unpublished data)
Almost two thirds of our sample had "ever operated" an ATV, with males twice as likely to report such experience. Almost every child with a family ATV reported ATV experience; however almost $60 \%$ of the children without a family ATV also reported ATV experience. Similarly, farm families were more likely to own ATVs, but children living on farms and in towns were equally experienced. This suggests that all rural children are at risk, and preventive programs should not target farm families, or families with ATVs, exclusively.

Although Manitoba law requires helmet use for all off-road vehicle riders, only one third of our sample reported always wearing a helmet. Unfortunately, farmers "when engaged in their occupation" are exempt and therefore may not wear a helmet as often as parents who are not exempt. ${ }^{11}$ However, rates of helmet use by occupation is unknown. Our rate of helmet use is significantly lower than that reported in the literature. Documentation of helmet use by ATV riders is a problem common to retrospective series in the literature, with rates between $12 \%$ and $65 \% .{ }^{17}$ Helmet use (when reported) varies between $60 \%$ and $84 \%$ for children and between $21 \%$ and $73 \%$ for adults and children. ${ }^{213-15}{ }^{18-20}$ In fatal crashes, riders are rarely found wearing helmets. ${ }^{21} 22$

The use of other protective clothing in our sample was quite variable. The lack of eye protection was most concerning, with $60 \%$ of children reporting never wearing any form of eye protection. The ATV Safety Institute strongly recommends the use of approved goggles or a face shield. ${ }^{17}$ The lack of proper footwear is also of concern, because the most common injuries associated with ATVs involve the lower leg and foot. One mechanism of injury is the foot slipping or the lower leg getting caught under the rear wheel or in a working part of the vehicle. ${ }^{1418}$ In a Manitoba series of 375 children admitted with off-road vehicle trauma, 105 fractures were documented in 68 ATV riders, $47 \%$ of which were in the lower extremity. ${ }^{13} 14$

Another finding of concern is the prevalence of "doubling", or carrying a passenger. Almost half of our sample reported giving rides on their ATVs. These vehicles were not designed to carry a passenger. In fact, doubling is frequently cited as a potential contributing factor in both fatal and non-fatal crashes, and has been strongly discouraged by ATV authorities. ${ }^{1415182022}$

Although Manitoba law prohibits driving on roadways, over one third reported always or 
sometimes riding on public roads. Most non-fatal ATV crashes occur in a variety of offroad areas. ${ }^{15} 20$ However fatal crashes occur most commonly on paved roadways and involve collisions with another motor vehicle. ${ }^{21} 22$

Boys were much more likely to have ATV experience. Although the only significant gender difference was for glove use, males reported more frequent use of helmets and protective clothing than females. These trends may be significant in a larger sample. Logic suggests that these more experienced and perhaps more "serious" riders are, in fact, more keen to wear "ATV gear" than their female peers.

Similarly, the trend toward more positive safety behaviours among town children may reflect the social context of ATV riding in the two respective settings. For example, farm children may be riding for occupational related purposes, with short trips on family property perceived as not requiring protective gear. These issues require further study for clarification.

\section{Implications for prevention}

Legislation and education are the two major strategies to prevent ATV injury. A recent review concluded that legislation is more effective than education in preventing adolescent injury due to recreational activities, including driving and motorcycling. ${ }^{23}$ Although legislation requiring helmet use, prohibiting ATV use on roads and by children was recommended by injury experts almost a decade ago, ${ }^{145}$ laws vary widely among regions and are difficult to enforce, due to the off-road nature of ATV riding. In a six month period between July 1994 and February 1995 in Manitoba, 21 riders were fined for helmet violations, two for careless operation of an off-road vehicle, and five for allowing a child to ride without supervision. ${ }^{24}$ Foley examined the effect of legislation on ATV safety behaviours in a cross sectional survey and observational field study of 269 ATV riders in several states with and without mandatory helmet use laws in the summers of 1988 and $1989 .{ }^{16}$ Riders were more likely to wear a helmet in areas with helmet use laws $\left(95 \% v 62 \%, \chi^{2}=44.446, \mathrm{df}=1\right.$, $\mathrm{p}<0.001$ ), and were also more likely to wear protective clothing and were observed riding double less often. Enforcement of local legislation should be given a higher priority, perhaps through education of law enforcement officers regarding the dangers of ATV riding in children. Intermittent, perhaps seasonal, intensive "spot" rider checks at popular off-road riding areas with monetary fines and driver license penalties applied to the parent could increase helmet use and child supervision on ATVs.

Rider education has the potential to increase safety behaviours and decrease injuries, especially if linked to the licensing process. Mandatory driver licensing and training, though not required in Manitoba, are a prerequisite for young riders in some regions. Driver education has been extensively studied for automobiles and for motorcycles, ${ }^{16}{ }^{23}$ with disappointing results. Although students may show superior skills and an initial period of reduced collisions, there has not been an overall reduction in crashes. Driver education may encourage younger students to obtain their licenses, drive at a younger age, and in fact increase the collision risk when compared with their untrained peers. However, almost no information is available for off-road vehicle safety training programs and their evaluation, and comparison to automobile and on-road motorcycle driver training is limited. Foley also examined the effect of education on ATV safety behaviours in the $1988-89$ observational study. ${ }^{16}$ Riders were 4.3 times more likely to wear a helmet if they had received formal ATV training. We are currently examining the effectiveness of the Canada Safety Council ATV riders course, in a randomized trial in young adolescent riders. Education of parents and ATV sales representatives regarding the dangers of ATVs in children must continue, to ensure that the smaller and younger children ride appropriate sized vehicles only, and always with direct adult supervision.

ATV manufacturers could play a greater part in ATV injury prevention, particularly in areas outside the US, where voluntary standards already exist. ATV courses have been offered free of charge to purchasers of new ATVs in the US, and dealers are subject to random monitoring of compliance with regulations. Certain vehicle modifications have the potential to reduce the incidence and severity of injury: rear wheel guards may prevent crashes due to the foot being caught by the wheel; throttle governors, available on some models, allow the throttle to be locked at a desired maximum and effectively act as a speed limit; modifications of seat design could discourage carrying passengers; remote control, available on some models, enable motor shut-off by a supervising adult and could reduce injuries in children. ${ }^{182} 25$ Helmets and other protective equipment could be offered free with the sale of new ATVs, as a purchase incentive.

Local participation by community and user groups in ATV injury prevention discussions has produced useful and unique approaches. A northern Manitoba snowmobile user group has addressed the importance of peer acceptance and self image as barriers to helmet use, by having each child design their one-of-a-kind professionally painted helmets. This has encouraged healthy helmet competition between young riders, and the kids wear their helmets with pride.

An effective program to improve ATV safety and reduce injuries will require a multifaceted approach, combining legislation and education, and involving riders, parents, ATV sales representatives and manufacturers, government agencies, and community organizations.

Appreciation is expressed to Dr M Tenenbein and Dr M Moffatt for review of this manuscript, to the Manitoba Association of Agricultural Societies, Farm Safety Committee and IMof Agricultural Societies, Farm Safety Committee and IM-
PACT staff for arranging and administering the survey, and to PACT staff for arranging and administering the survey, and to
all the students who participated. This study was completed 
during a research fellowship (LW) funded by the Children's Hospital Research Foundation.

Kubala MJ, Shrontz CE. All-terrain vehicle accidents. Tex Med 1987;83:27-30.

2 Percy EC, Duffey JP. All-terrain vehicle injuries: a sport out Percy EC, Duffey JP. All-terrain vehicle ini

3 Greene MA, Metzler MH. Trauma associated with three Greene MA, Metzler MH. Trauma associated with three and four-wheeled all-terrain vehicles. F Trauma 1988;28: $391-4$

4 Canadian Pediatric Society Accident Prevention Committee. Two-, three- and four-wheel unlicensed off-road vehicles. Can Med Assoc f 1987;136:119-20

5 Verhalen RD. Who's right about all-terrain vehicles? Bull $N$ $Y$ Acad Med 1988;64:804-9.

6 United States Consumer Product Safety Commission. Update of all-terrain vehicle deaths and injuries using data available as of fune 30, 1995. Washington, DC: US CPSC, 1995

7 American Academy of Pediatrics Committee on Injury and Poison Prevention. All-terrain vehicles: two-, three-, and four-wheeled unlicensed motorized vehicles Pediatrics 1987;79:306-8.

8 Cowell HR. All-terrain vehicles [Editorial]. F Bone foint Surg 1988;70A: 159 .

9 Canadian:159. Injury Reporting and Prevention Program. Injury data from the database of the Canadian Program. Injury data from the database of the Canadian
Hospitals Injury Reporting and Prevention Program.

10 Manitoba Health. Manitoba population report: Fune 1, 1994. Winnipeg, Manitoba: Manitoba Health, 1994

11 Manitoba Highways and Transportation Driver and Vehicle Licencing. Off-road vehicles. Winnipeg: Manitoba Highways and Transportation Driver and Vehicle Licencing.

12 US Consumer Product Safety Commission. Young people under the age of 16 should not ride adult-size ATVs: safety alert. Washington, DC: US CPSC

13 Cardoso ER, Pyper A. Pediatric head injury caused by off-road vehicle accidents. Can F Neurol Sci 1989;16:336-9.
14 Pyper JA, Black GB. Orthopaedic injuries in children associated with the use of off-road vehicles. F Bone foint Surg 1988;70A:275-84.

15 Krane BD, Ricci MA, Sweeney WB, et al. All-terrain vehicle injuries: a review at a rural level II trauma center. Am Surg 1988;54:471-4.

16 Foley JP. The effect of law and training on all-terrain vehicle riders'safety-related behaviors. West Lafayette, Indiana: Purdue University, 1990. (PhD thesis.)

17 ATV Safety Institute. ATV ridercourse handbook. USA: ATV Safety Institute, 1995.

18 Ganos D, Crady S, Poortenga S, et al. Trauma associated with three- and four-wheeled all-terrain vehicles: is the four-wheeler an unrecognized health hazard? Am Surg 1988;54:429-33.

19 Trager GW, Grayman G, Harr S. All-terrain vehicle accidents: the experience of one hospital located near a major recreational area. Ann Emerg Med 1986;15:1293-6.

20 Maynard FM, Krasnick R. Analysis of recreational off-road vehicle accidents resulting in spinal cord injury. Ann Emerg Med 1988;17:30-3.

21 Hargarten SW. All-terrain vehicle mortality in Wisconsin: a case study in injury control. Am f Emerg Med 1991;9:14952 .

22 Copeland AR. All-terrain vehicles: dangerous at any speed. Am $\mathcal{F}$ Forensic Med Pathol 1987;8:225-8.

23 Munro J, Coleman P, Nicholl J, et al. Can we prevent accidental injury to adolescents? A systematic review of the evidence. Inj Prev 1995;1:249-55.

24 Page-Valin L, Simpson HM, Warren RA. Effectiveness of driver education: what do we know and where do we go from here? Ottawa, Ontario: Traffic Injury Research Foundation of Canada, 1977.

25 Sewell CM, Pine JS, Hull HF. Injuries and fatalities associated with off-road three-wheeled all-terrain vehicles. West $\mathcal{F}$ Med 1987;146:497-8.

\section{US study tells skaters where to put the pads}

"A recent study suggests that more than one third of all serious skating injuries ... could be prevented if all skaters wore wrist guards and elbow pads" (New York Times, November 1996).

\section{Couple lose second child to drowning}

"A couple whose daughter drowned in the family pool two years ago has lost their youngest son, drowned under similar circumstances. In both cases, the children apparently gained access to the backyard pool through doors leading to a patio deck above the pool" (Gazette, June 1997).

\section{Golden Bull award for pram definition}

The British government has scooped six of the nine Golden Bull awards given this year for incomprehensible English. The Department of Trade and Industry earned special mention for its definition of a pram. "A wheeled vehicle designed for the transport in a seated or semirecumbent position of one or two babies or infants or any carrycot or transporter thereof".

Editor's note: Alternative, more succinct, equally comprehensive definitions of a pram should be sent to the editor for his amusement. 